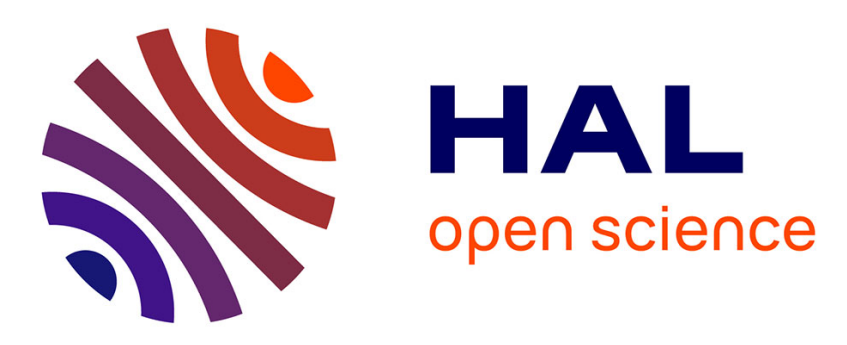

\title{
Escape migration decisions in Eurasian Woodcocks: insights from survival analyses using large-scale recovery data
}

Guillaume Péron, Yves Ferrand, François Gossmann, Claudine Bastat, Michel Guénézan, Olivier Gimenez

\section{To cite this version:}

Guillaume Péron, Yves Ferrand, François Gossmann, Claudine Bastat, Michel Guénézan, et al.. Escape migration decisions in Eurasian Woodcocks: insights from survival analyses using large-scale recovery data. Behavioral Ecology and Sociobiology, 2011, 65, pp.1949 - 1955. 10.1007/s00265-011-1204-4 . hal-03499309

\section{HAL Id: hal-03499309 \\ https://hal.science/hal-03499309}

Submitted on 25 Dec 2021

HAL is a multi-disciplinary open access archive for the deposit and dissemination of scientific research documents, whether they are published or not. The documents may come from teaching and research institutions in France or abroad, or from public or private research centers.
L'archive ouverte pluridisciplinaire HAL, est destinée au dépôt et à la diffusion de documents scientifiques de niveau recherche, publiés ou non, émanant des établissements d'enseignement et de recherche français ou étrangers, des laboratoires publics ou privés. 
Escape migration decisions in Eurasian Woodcocks: insights from survival analyses using large-scale recovery data

Guillaume Péron ${ }^{(1)} *$

Yves Ferrand $^{(2)}$

François Gossmann ${ }^{(3)}$

Claudine Bastat ${ }^{(3)}$

Michel Guénézan ${ }^{(3)}$

Olivier Gimenez ${ }^{(1)}$

(1) Centre d'Ecologie Evolutive et Fonctionnelle UMR 5175. CNRS, 1919 Route de Mende 34293 Montpellier Cedex 5, France

${ }^{(2)}$ Office National de la Chasse et de la Faune Sauvage, Direction des Etudes et de la Recherche, Saint-Benoist, 78610 Auffargis, France

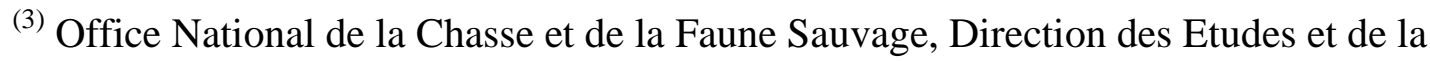
Recherche, 39 boulevard Albert Einstein, CS 42355, 44323 Nantes Cedex 3, France

*Corresponding author: email : peron_guillaume@yahoo.fr

$$
\text { Fax: +33(0) } 467412138
$$

Running title: Weather, survival and escape migration 
Abstract During unpredictable adverse conditions, endotherms can engage in emergency behaviours (movement, torpor, hyperphagia) to maintain energy balance and reduce mortality hazards. Bird 'escape migration' is one of the most visible of these behaviours. In this study we focus on a Eurasian Woodcock Scolopax rusticola population. Seasonal migrations bring this population from its breeding grounds in Eastern and Northern Europe to its wintering grounds in France. A varying number of these birds are also regularly reported from Spain, supposedly during additional escape movements that occur in winter. Using models that account for the imperfect detection rate of individuals and a large ( $>44,000$ individuals) dataset combining information from the wintering and breeding ranges, we show that severe winters significantly reduced survival probability, but that migration to Spain increased only during the most intense cold spell that occurred over the 20 year study period. This suggests that the decision to resume migration during the winter is submitted to a threshold mechanism, which we discuss in the light of current models of migratory behaviour.

Key words Allostasis, Capture-mark-recapture, capture-recovery, Climate change, Optimal migration, Recoveries. 
1

2 Extreme weather events put the energy allocation trade-offs of individuals into question

3 (Boyle et al. 2010). Documented consequences include massive death tolls (e.g., Cezilly et al.

4 1996), sometimes associated with rapid microevolution (Brown and Brown 1998), and

\section{Introduction}

generally with major consequences on population dynamics (Coulson et al. 2001; Saether et al. 2004; Sutherland 2006). Iteroparous species thus endure strong selective pressures to evolve coping strategies. Birds have been especially studied in that respect because of their highly visible migrations. Contrasting the well-known compulsory seasonal migration of many species, which appears as an answer to predictable changes in the environment, escape migration refers to the facultative movement of a varying fraction of the population, in response to unpredictable adverse conditions (Berthold 1995; Newton 2008). Examples of these adverse conditions triggering escape migration include poor seed production in boreal forests regulating the winter invasions of nomadic boreal finches Fringillidae and waxwings Bombycilla sp. (Berthold 1995; Newton 2008), and hot temperatures and droughts triggering movements in arid habitats (e.g., Great Bustard Otis tarda; Alonso et al. 2009). The associated physiological mechanisms are only starting to be quantified (Lohmus et al. 2003; Landys et al. 2006; Boyle et al. 2010). The fitness consequences of these individual migration decisions have moreover very rarely been measured (but see Rivalan et al. 2007). While the ability to escape adverse conditions should enhance survival probability, non-negligible costs of migration are expected. One thereby expects a trade-off between the risks of migration and the risks of remaining in place and enduring adverse conditions (Alerstam and Lindström 1990). Here we study the demographic consequences of such individual trade-off. We consider three hypotheses describing a continuum of potential behavioral responses to exceptional weather events. (1) Escape migration probability could be higher in years with an event than in years without one, indicating that escape migration is less costly 
than enduring adverse conditions. (2) Escape migration probability could be low and/or constant, or be explained by factors other than weather (population density, e.g.: Fowler 2009), indicating that escape migration is more costly than enduring adverse conditions. (3) The answer to extreme weather events could be submitted to a threshold mechanism: below a given intensity, few individuals modify their behavior while above that threshold, individuals start expressing escape behaviors. These three hypotheses are all based on the existence of a cost of remaining in place during adverse conditions, but differ in the way this cost scales to the cost of migration. They can be tested by comparing the variation in the frequency of migratory movements and in the weather conditions. We studied a migratory game species, the Eurasian Woodcock Scolopax rusticola, and in particular the population that winters in France. These birds are usually particularly faithful to their wintering site (Gossmann et al. 1994), but some are recovered in Spain (and to a lesser extent Northern Africa) each year. We tested whether those Spanish recoveries corresponded to individuals that had migrated further in answer to weather, which has never been formally investigated before. Capture-recapture-recovery models make it possible to estimate survival and migration probabilities of the banded individuals, while accounting for the fact that not all dead individuals are reported and not all live individuals are recaptured. First, we analyzed the capture-recovery data to investigate between-year variations in survival probability and their relation to weather, in order to test for the existence of a cost of harsh winter weather. Second, we estimated the temporal variation in the proportion of birds that reached Spain each winter. We used that proportion as a measure for the probability of escape migration, which made it possible to test the above-mentioned three hypotheses regarding migration decisions. 


\section{Material and Methods}

\section{Study individuals}

On the winter grounds most woodcocks commute between night-time feeding grounds (mainly meadows) where banding occurs and day-time roost sites in forests where hunting occurs (Duriez et al. 2005a). The study individuals were marked with metal bands, from the beginning of October to the end of February. Recoveries (reports of hunted banded birds) occurred in France (usual wintering grounds), in Spain (unusual wintering ground) and in Eastern and Northern Europe (spring migration stopovers and breeding grounds). We used the data collected between October 1989 and February 2009 (20 years), which corresponded to 44,902 different individuals, 12,078 of which were recovered in France, 263 in Spain and 737 in Eastern Europe, plus 2,873 different recapture events in France.

Hunting pressure is suspected to vary subsequently between banding locations, which might influence the estimation of survival. To account for variation in hunting pressure while estimating survival, we used a proxy that we built as follows. For each locality, the percentage of banded birds that were recovered through hunting less than $10 \mathrm{~km}$ from their banding place (as opposed to the remaining recoveries that occurred elsewhere during weather-mediated dispersal) were considered to be representative of the local hunting pressure. Localities were then divided between two groups corresponding to above-median (high) and below-median (low) hunting pressure. We refer to this two-level variable as the hunting pressure index (HPI) hereafter. We restricted the dataset to the 714 localities where at least 20 birds have been banded over the study period. Yearly location-specific sample sizes did not allow the computation of a yearly HPI for each location; in the following we thus account for the temporal average of hunting pressure using HPI. 


\section{Weather variables}

For each winter (October to February) of our 20-year study period, we obtained four weather variables from nine Météo France stations spread across the French wintering range of our study population: the number of freezing days, the average winter temperature, the minimum recorded temperature, and the amount of precipitation (ESM 1). We used principal component analyses (PCA; Jolliffe 2002) as implemented in the R-package ADE 4 (Thioulouse et al. 1997) to create one summary index for each weather variable. Detail about these indexes is provided in ESM 1 (Fig. S1: locations of the Météo France stations, Table S1: correlation between summary indexes and absence of temporal trend, Fig. S3: correlation circles). To avoid using highly correlated explanatory variables in our capture-recovery models, we selected the two most biologically relevant indexes (see discussion) out of four that were available: the variation in the total number of freezing days recorded over the winter, denoted $\mathrm{N}_{<0}$, and the variation in the total amount of precipitation recorded over the winter, denoted $\mathrm{P}_{\text {tot. }}$ The relationship between these weather indexes and the station-specific weather data is described in Fig. S3 in ESM1. Further details on the use of such condensed weather indexes in capture-recapture analyses are found in Grosbois et al. (2008).

These weather indexes described the average conditions during winter. However it is generally understood that extreme events are of greater influence than average conditions (e.g., Boyle et al. 2010). We thereby also obtained from Météo France a classification of winters according to the occurrence and severity of exceptional events, namely cold spells (http://comprendre.meteofrance.com/content/2009/10/21331-48.pdf; in French). This classification is based on the comparison of daily mean temperatures with the long-term average. The period between December 251996 and January 81997 was qualified as 'high intensity cold spell' by Météo France. We hereafter use the notation 'c96' when we 
distinguish winter 1996-1997 from other winters in a model. Less intense cold spells occurred in the winters 1990-91, 2001-02, 2002-03, 2005-06, and 2008-09.

From the woodcock's natural-history, we predicted that $\mathrm{N}_{<0}$ and $\mathrm{P}_{\text {tot }}$ should correlate positively and negatively, respectively, to starvation risk and thus mortality probability (see the discussion section for more detail and references). The decision to migrate should also depend on these variables under hypothesis 1 , but should be independent of weather in hypothesis 2, and should vary only during the most intense cold spell (c96) under hypothesis 3. We also tried models in which the demographic parameters followed a temporal trend either alone or in addition to the effect of the weather variables.

\section{Capture-recovery models with escape migration and seasonal variation}

We built multistate capture-recovery models (e.g., Gauthier and Lebreton 2008) using program E-SURGE (version 1.6.4; Choquet et al. 2009). These models are parameterized using survival probabilities $s_{t}$ (the probability for a bird to survive between year $t$ and $t+1$ ), migration probabilities $\psi_{t}$ (the probability for a bird to migrate to Spain during the winter of year $t$ ), recovery probabilities $\mathrm{r}_{t}$ (the probability for a bird dying during year $t$ to have died from hunting and been reported as such to the ONCFS woodcock network), and recapture probabilities $\mathrm{p}_{t}$ (the probability for a bird alive and already wearing a band to be re-trapped during the banding sessions in winter in France during year $t$ ). For methodological reasons (parameter identifiability), the decision to migrate to Spain or remain in France was modeled to occur at the beginning of each winter, i.e., before winter survival. This is a constraint inherent to the seasonal capture recapture model we used and not a biological hypothesis. We also adapted this general framework to the woodcock case as follows. (i) We distinguished 'winter' (October to February) and 'summer' (March to September) survival probabilities. (ii) We distinguished 'French', 'Spanish', and 'summer' (in Eastern Europe) recovery probabilities. (iii) Following Tavecchia et al. (2002), winter recovery probability was divided 
120 between direct (same winter as the banding) and indirect (subsequent winters) recovery

121 probabilities. (iv) Banding and hunting occurred roughly at the same time in winter. Thereby,

122 the months at banding influenced the duration for which an individual was submitted to

123 mortality hazards during its first winter after banding. We accommodated that issue by

124 computing monthly winter survival probabilities (denoted $\widetilde{\mathrm{s}}_{\mathrm{w}, \mathrm{t}}$ )We raised that monthly

125 survival to the power corresponding to the number of months the individual was exposed to

126 mortality hazards (see ESM 2 for details on the practical implementation). For example,

127 individuals ringed in December had a first winter survival probability of $\mathrm{s}_{\mathrm{w}, \mathrm{t}_{1}}=\widetilde{\mathrm{s}}_{\mathrm{w}, \mathrm{t}_{1}}^{3}$, instead

128 of $\mathrm{s}_{\mathrm{w}, \mathrm{t}_{1}}=\widetilde{\mathrm{s}}_{\mathrm{w}, \mathrm{t}_{1}}^{5}$ if they had been ringed in October.

129 Due to the computer burden, and because we observed numerous instabilities in the

130 likelihood optimization procedure, we ran the capture-recovery analysis in two steps. First, we

131 discarded the data from Spain and looked for the best model of winter survival probability in

132 France (step A hereafter). Based on general knowledge about avian and particularly gamebird

133 demography, confirmed by unpublished analyses, the following effects were not tested but

134 included a priori in the models:

135 - the effect of season (winter vs. summer) on survival and recovery probabilities,

136 - the effect of age (adults vs. juveniles) on winter and summer survival probability,

137 - the effect of HPI on winter survival and recovery probabilities,

138 - between-year variations in winter and summer survival probability,

139 - between-year variations in recapture and recovery probabilities in France,

140 - constant recovery probability in Eastern Europe,

141 The model selection in step A focused on the effect of weather covariates on winter

142 survival probability (Grosbois et al. 2008). Next (step B), we added to the data the recoveries

143 from Spain. We now needed to include the migration probabilities in the model. We 
144 investigated between-year variations and the effect of weather variables on migration

145 probability.

\section{Results}

\section{Step A: Weather impact on winter survival in France}

The model selection procedure indicated that the additive effects of $\mathrm{N}_{<0}$ and $\mathrm{P}_{\text {tot }}$, acting in conjunction with a linear temporal trend was preferred over the full time-dependent model (Table 1: Model A5 vs. A2; Fig. 1). The amount of variance in survival probability explained by the covariates in this model reached $77 \%$, of which $56 \%$ were accounted for by the temporal trend and $21 \%$ by the weather variables (Table 1: Models A5, A3 and A4). From Fig. 1 it can be seen that only the winter 2002-2003 was wrongly described in model A5, and that the cold spell of winter 1996-1997 had no marked impact on survival probability.

Our analyses controlled for the effect of hunting pressure, age, and season. Briefly, we found that HPI correlated with survival and recovery probability in opposite directions, that juveniles survived less than adults, and that survival probability over the seven months of summer was of the same order of magnitude as survival probability over the five months of winter.

\section{Step B: Weather impact on migration probability}

The data supported the existence of between-year variation in the proportion of birds migrating to Spain (Table 2). This variation was successfully retrieved by a temporal trend and the separate modelling of winter 1996-1997 during which a high intensity cold spell occurred (Table 2; Fig. 2). After accounting for the 1996-1997 cold spell, the additive effects of the temporal trend captured $38 \%$ of the remaining variance (i.e., $14 \%$ of the total variance; Table 2: Model B6 vs. Model B4). Adding the effect of weather variables onto the temporal trend only slightly improved the fit (Table 2: Model B6 vs. B7). 


\section{Discussion}

169

170

171

172

173

174

175

176

177

178

179

180

181

182

183

184

185

186

187

188

189

190

191

192

\section{The cost of enduring adverse conditions}

Our result that survival decreased during winters with numerous freezing days and little precipitation indicates a significant pressure for increased migration during those winters (Sutherland 2006; Rivalan et al. 2007; Boyle et al. 2010). The first explanatory hypothesis involves food availability. Indeed, during freezing days woodcocks cannot reach earthworm resource because of snow cover and frozen soils (Boos et al. 2005). Rain on the contrary softens soil and attracts earthworms to the surface (Gerard 1967; Duriez et al. 2006) making them more available to woodcocks (Duriez et al. 2005a; 2006). The second explanatory hypothesis involves thermoregulatory cost, which increases with falling temperatures (Duriez et al. 2004).

Our understanding of woodcock response to adverse weather would clearly benefit from a more focused documentation of these mechanisms. Woodcocks remaining in place during a cold spell might be those whose fat reserves were insufficient to resume migration (Alerstam and Lindström 1990), or they could by contrast be those whose fat reserves were sufficient to undergo a long period of deprivation without starving (Wingfield et al. 1998). It would be interesting to compare the fat load of woodcocks (Boos et al. 2005) hunted just after and just before a cold spell. In addition, it could be possible to directly document foraging effort and success under varying weather condition using the radio-tracking methodology described by Duriez et al. (2005b).

A methodological note is that it was not possible to estimate separately survival in France and Spain. This was not a problem of parameter identifiability which was checked using methods implemented in E-SURGE (Choquet et al. 2009), but rather a problem of optimization. When survival was different in France and Spain, the unobservable state 'alive in Spain' became a dummy one (i.e., with an associated survival rate of zero), leading to a 
193 model in which the estimated migration probability corresponded indeed to the overall

194 probability to migrate and die in Spain. Additional data, such as live encounters in Spain and

195 radio-tracking data, appear necessary to obtain a more biologically useful model in this case.

196

197

198

199

200

201

202

203

204

205

206

207

208

209

210

211

212

213

214

215

216

217

\section{The cost of escaping adverse conditions}

Escape migration to Spain was a rare behavior occurring in less than $1 \%$ of individuals during 'normal' years (Fig. 2). Escape migration must hence bear non-negligible costs. However, a notable increase in escape migration probability (up to c. $5 \%$ ) occurred during, and supposedly as a consequence of, the high intensity cold spell that hit France between December 251996 and January 8 1997. On the opposite, low-intensity cold spells did not impact migration probability (Fig. 2). There thus seems to be a threshold of cold spell intensity after which woodcocks resume southwards migration. Hypothesis 3 (escape migration is beneficial only during the most intense cold spells) was therefore the most supported. However, we recognize that additional data (more cold spell events) are required in order to rule out the possibility that the result was confounded by some unidentified factor.

The above considerations are in line with the Optimal Migration theory (Alerstam and Lindström 1990; Hedenstrom 2008). In this framework, the decision to leave the current location depends in part on the expected difference in resource availability between the current and more Southern sites. Time between departure from the breeding grounds and arrival to the wintering grounds is the preponderant 'currency' whose expenditure is optimized (Saffriel and Lavee, 1988; Hedenstrom 2008). Although this model of migratory behavior was developed to explain stopover strategies during seasonal, compulsory, longdistance migration, it can be extended to the case of a population already settled in its wintering grounds but having the option to perform additional movement. In this situation, time is not a constraint (since the individuals are already settled in the wintering areas and escape migration can be considered to have negligible impact on the timing of spring 
218 migration). The decision to leave is indeed expectedly driven by the balance between the risks

219 of starving if remaining in place versus resuming migration, i.e., energy is the currency to be

220 optimized. Our results seem to indicate that the expected benefits of resuming migration

221 exceeded costs only during the 1996-1997 cold spell. Interestingly, no particular drop in

222 survival was observed during that winter (Fig. 1), suggesting that escape migration enabled

223 many individuals to survive that particular cold spell. Lastly, migration to Spain might be a

224 two-step phenomenon. During cold spells, woodcocks are known move away from

225 continental climate and migrate towards the French coastlines. Migration to Spain might

226 occur as a secondary escape behavior, when conditions on the coast become unsustainable

227 too.

Proposed physiological mechanisms of escape migration

Allostasis models (Wingfield et al. 1998; McEwen and Wingfield 2003; Landys et al. 2006)

230 are based on the balance between the energy needed to merely survive (homeostatic level), the

231 energy spent in facultative activities, and the energy which is available in the environment.

232 The outcome is the allostatic load. As demand for energy increases (Duriez et al. 2004), the

233 allostatic load may rise above some critical threshold, triggering a physiological response

234 ('emergency life history stage'). One such response is an increase in glucocorticoid hormones

235 secretion (Landys et al. 2006). This increase has been hypothesized to trigger behaviors aimed

236 at offsetting the cost of adverse conditions (e.g., escape migration, increased food

237 consumption, reduced energy expenditure: Boyle et al. 2010; Landys et al. 2006; and

238 references therein). Plasticity of behavioural response may be explained by interactions with

239 the two cytoplasmic binding receptors for glucocorticoids each with distinct binding affinities.

240 Each could affect distinct behavioural responses depending upon the concentration of plasma

241 hormone. This would explain that, although increased during the 1996-1997 cold spell, escape

242 migration probability remained low at c. 5\%. We indeed suspect that only individuals with 
243 initially sufficient fat reserve can undertake escape migration, the remaining individuals being

244 compelled to stay in their current location (Alerstam and Lindström 1990) or flying shorter

245 distances (remaining in France). Cold spells being by nature unpredictable, and individuals

246 being available for capture only if they do not migrate, further tests of these hypotheses in the

247 woodcock system are challenging.

\section{Predictions in the face of climate change}

249 A temporal trend was apparent in both the winter survival and escape migration probabilities.

250 Both parameters increased with time, and the trend was more marked in survival. In the

251 absence of a clear trend in the local weather variables (ESM 1), it is unlikely that the time

252 effects on demographic parameters reflected an impact of the ongoing climate change. We

253 suggest variation in sampling procedures (change in banding locations) through time as a

254 potential explanation, but this requires further investigation. If a true biological result, these

255 increasing trends might stem from an increase in breeding habitat availability (farmland

256 abandonment in Eastern and Northern Europe). Our results nevertheless have implications for

257 the management of woodcock as a game species in the face of climate change. Milder winters

258 (less freezing days, more rain) are predicted in the woodcock French wintering range (IPCC

259 2007). Conditions are therefore expected to get better for woodcocks. However, climate

260 models also predict a rise in the frequency of exceptional weather events (IPCC 2007), which

261 might imply more cold spells, and also more drought and fire events in the breeding range. An

262 improvement upon our models would then be their use in a prospective framework including

263 variation in both average conditions and in the regime of stochasticity (e.g., Gotelli and

264 Ellison 2001). Such a study would answer questions related to selection pressure for more or

265 less migratoriness, and the demographic consequences including future population size and

266 winter range. 


\section{Acknowledgments}

268 Nothing would have been possible without the important field work and dynamism of the 269 banders of the ONCFS/FNC/FDC Woodcock Network. Parts of this manuscript were written

270 while G.P. was supported by a Quinney post-doctoral fellowship at Utah State University,

271 USA. O.G. was supported by a grant from Agence Nationale de la Recherche (ANR-08-JCJC-

272 0088-01). We thank B. Doligez and two anonymous reviewers for very useful insights on 273 previous drafts of this article. 


\section{References}

Alerstam T, Lindström A (1990) Optimal bird migration: the relative importance of time, energy and safety. In: Gwinner E (ed) Bird Migration: Physiology and Ecophysiology. Springer, Berlin. pp 331-351.

Alonso JC, Palacin C, Alonso JA, Martin CA (2009) Post-breeding migration in male great bustards: low tolerance of the heaviest Palaearctic bird to summer heat. Behavioral Ecology and Sociobiology 63:1705-1715.

Berthold P (1995) Control of bird migration. Springer, New York.

Boos M, Boidot JP, Robin JP (2005) Body condition in the Eurasian Woodcock wintering in the West of France: practical study for wildlife management during cold spells. Wildlife Biology in Practice 1: 15-23.

Boyle WA, Norris DR, Guglielmo CG (2010) Storms drive altitudinal migration in a tropical bird. Proceedings of the Royal Society B-Biological Sciences 277: 2511-2519.

Brown CR, Brown MB (1998) Intense natural selection on body size and wing and tail asymmetry in cliff swallows during severe weather. Evolution 52: 1461-1475.

Brownie C, Anderson DR, Burnham KP, Robson DS (1985) Statistical inference from band recovery data - a handbook, 2nd ed., Washington, D.C., U.S. Fish Wildl. Serv. Res. Publ.

Cezilly F, Viallefont A Boy V, Johnson AR (1996) Annual variation in survival and breeding probability in Greater Flamingos. Ecology 77: 1143-1150.

Choquet R, Rouan L, Pradel R (2009) Program E-SURGE: a software application for fitting Multievent models. In: Thomson DL, Cooch EG, Conroy MJ (eds) Modeling Demographic Processes in Marked Populations. Springer, New York. 
Coulson T, Catchpole EA, Albon SD et al. (2001) Age, sex, density winter weather, and population crashes in Soay sheep. Science 292: 1528-1531.

Duriez O, Pastout-Lucchini L, Boos M, Chastel O, Fritz H, Ferrand Y, and Clobert J (2004) Low levels of energy expenditure in a nocturnal, forest-dwelling wader, the Eurasian Woodcock Scolopax rusticola. Ardea 92:31-42.

Duriez O, Ferrand Y, Binet F, Corda E, Gossmann F, Fritz H (2005a) Habitat selection of the Eurasian woodcock in winter in relation to earthworms availability. Biological Conservation 122: 479-490.

Duriez O, Fritz H, Binet F, Tremblay Y, Ferrand Y (2005b) Individual activity rates in wintering Eurasian woodcocks: starvation versus predation risk trade-off? Animal Behaviour 69:39-49.

Duriez O, Ferrand Y, Binet F (2006) An adapted method for sampling earthworms at night in wildlife studies. Journal of Wildlife Management 70:852-858.

Fowler MS (2009) Density dependent dispersal decisions and the Allee effect. Oikos 118: 604-614.

Gauthier G, Lebreton JD (2008) Analysis of band-recovery data in a multistate capturerecapture framework. Canadian Journal of Statistics 36: 59-73.

Gerard BM (1967) Factors affecting earthworms in pastures. Journal of Animal Ecology 36: $235-252$.

Gossmann F, Ferrand Y Bastat C (1994) Mortalité hivernale des bécasses des bois en France d'après les reprises de bagues. IWRB Publication 31: 8-14. In French.

Gotelli NJ, Ellison AM (2006) Forecasting extinction risk with nonstationary matrix models. Ecological Applications 16:51-61.

Grosbois V, Gimenez O, Gaillard JM et al. (2008) Assessing the impact of climate variation on survival in vertebrate populations. Biological Reviews 83: 357-399. 
Hedenstrom A (2008). Adaptations to migration in birds: behavioural strategies, morphology and scaling effects. Philosophical Transactions of the Royal Society B-Biological Sciences 363:287-299.

IPCC (2007) Contribution of Working Group II to the Fourth Assessment Report of the Intergovernmental Panel on Climate Change. Cambridge University Press, Cambridge, UK.

Jolliffe IT (2002) Principal Component Analysis, 2nd ed. Springer, New York.

Landys MM, Piersma T, Ramenofsky M, Wingfield JC (2004) Role of the low-affinity glucocorticoid receptor in the regulation of behavior and energy metabolism in the migratory red knot Calidris canutus islandica. Physiological and Biochemical Zoology 77: 658-668.

Landys MM, Ramenofsky M, Wingfield JC (2006) Actions of glucocorticoids at a seasonal baseline as compared to stress-related levels in the regulation of periodic life processes. General and Comparative Endocrinology 148: 132-149.

Lohmus M, Sandberg R, Holberton RL, Moore FR (2003) Corticosterone levels in relation to migratory readiness in red-eyed vireos (Vireo olivaceus). Behavioral Ecology and Sociobiology 54:233-239.

McEwen BS, Wingfield JC (2003) The concept of allostasis in biology and biomedicine. Hormones and Behavior 43: 2-15.

Newton, I. (2008) The migration ecology of birds. Academic Press, London.

Rivalan P, Frederiksen M, Lois G, Julliard R (2007) Contrasting responses of migration strategies in two European thrushes to climate change. Global Change Biology 13: 275-287.

Saether BE, Sutherland WJ, Engen S (2004) Climate influences on avian population dynamics. Birds and Climate Change 35: 185-209. 
Safriel UN, Lavee N (1988) Weight changes of cross-desert migrants at an oasis - do energetic considerations alone determine the length of stopover. Oecologia 76:611619.

Sutherland WJ (2006) Predicting the ecological consequences of environmental change: a review of the methods. Journal of Applied Ecology 43: 599-616.

Tavecchia G, Pradel R, Gossmann F, Bastat C, Ferrand Y, Lebreton JD (2002) Temporal variation in annual survival probability of the Eurasian woodcock Scolopax rusticola wintering in France. Wildlife Biology 8: 21-30.

Thioulouse J, Chessel D, Dolédec S, Olivier JM (1997) ADE-4: a multivariate analysis and graphical display software. Statistics and Computing 7: 75-83.

Wingfield JC, Maney DL, Breuner CW, Jacobs JD, Lynn S, Ramenofsky M, Richardson RD (1998) Ecological bases of hormone-behavior interactions: The "emergency life history stage". American Zoologist 38: 191-206. 


\section{Tables}

Table1 Model selection for the effect of weather variables on winter survival in France (step A). Given is the model structure for winter survival $(\varphi)$, departing from known effects of Age (adult vs. juveniles) and hunting pressure (HPI). $t$ denotes the full year effect (20 parameters). $\mathrm{T}$ denotes a temporal trend. $\mathrm{N}_{<0}$ represents the effect of the number of freezing day per winter. $\mathrm{P}_{\text {tot }}$ represents the amount of precipitation per winter. Formulas for the other model parameters (summer survival, resighting, and recovery probabilities) are omitted for clarity and did not vary among models. \#p, Dev, and $\triangle \mathrm{AIC}$ stand for number of parameters, deviance, and difference in AIC score to the preferred model. Model with lowest AIC is in bold; it has more than two points difference with the nearest model. F-values refer to the test of the effect of the considered time-dependent variable against Model A2 (full time dependence), while accounting for the overdispersion in Model A1 (time-independence). See Grosbois et al. (2008) for detail on these tests.

\begin{tabular}{|c|c|c|c|c|c|c|c|}
\hline \multirow[b]{3}{*}{ \# } & \multirow[b]{3}{*}{$\varphi$} & \multirow[b]{3}{*}{$\# p$} & \multirow[b]{3}{*}{ Dev } & \multirow[b]{3}{*}{$\Delta \mathrm{AIC}$} & \multicolumn{2}{|c|}{ ANODEV } & \multirow[b]{3}{*}{$\mathrm{r}^{2}$} \\
\hline & & & & & F- & $\mathrm{P}-$ & \\
\hline & & & & & value & value & \\
\hline A1 & Age $+\mathrm{HPI}$ & 64 & 81358.9 & 89.8 & & & \\
\hline $\mathrm{A} 2$ & Age $+\mathrm{HPI}+\mathrm{t}$ & 83 & 81234.0 & 2.9 & & & \\
\hline A3 & Age+HPI+T & 65 & 81288.1 & 21 & 45.93 & $<10^{-4}$ & 0.56 \\
\hline A4 & Age $+\mathrm{HPI}+\mathrm{N}_{<0}+\mathrm{P}_{\text {tot }}$ & 66 & 81333.7 & 68.6 & 16.34 & $<10^{-4}$ & 0.21 \\
\hline A5 & Age $+\mathrm{HPI}+\mathrm{N}_{<0}+\mathrm{P}_{\text {tot }}+\mathrm{T}$ & 67 & 81263.1 & $\mathbf{0}$ & 62.13 & $<10^{-4}$ & 0.77 \\
\hline
\end{tabular}


Table 2 Model selection for the probability to migrate from France to Spain during the winter (step B). Given is the model structure for migration probability $(\psi)$ and for recovery probability in Spain $\left(\mathrm{r}_{\mathrm{SP}}\right)$. A dot denotes that the corresponding parameter is constant. $\mathrm{t}$ denotes the full year effect (20 parameters). $\mathrm{N}_{<0}$ represents the effect of the number of freezing day per winter. $\mathrm{P}_{\text {tot }}$ represents the amount of precipitation per winter. c96 denotes the effect of the intense cold spell that occurred during the winter 1996-1997. T denotes a temporal trend. Formulas for the other model parameters (survival, resighting, and recovery probabilities in France) are omitted for clarity and did not vary among models. \#p, Dev, and $\triangle \mathrm{AIC}$ stand for number of parameters, deviance, and difference in AIC score to the preferred model. Model with lowest AIC are in bold; they have more than two points difference with the nearest model. F-values refer to the test of the effect of the considered time-dependent variable against Model B2 (full time dependence), while accounting for the overdispersion in Model B1 (time-independence). See Grosbois et al. (2008) for detail on these tests.

\begin{tabular}{|c|c|c|c|c|c|c|c|c|}
\hline \multirow{3}{*}{$\begin{array}{l}\# \\
\mathrm{~B} 1\end{array}$} & \multirow{3}{*}{$\begin{array}{c}\psi \\
.\end{array}$} & \multirow{3}{*}{$\frac{\mathrm{r}_{\mathrm{SP}}}{\mathrm{t}}$} & \multirow{3}{*}{$\begin{array}{l}\# p \\
87\end{array}$} & \multirow[b]{2}{*}{ Dev } & \multirow[b]{2}{*}{$\Delta \mathrm{AIC}$} & \multicolumn{3}{|c|}{ ANODEV } \\
\hline & & & & & & F-value & P-value & $\mathrm{r}^{2}$ \\
\hline & & & & 83515.7 & 61.0 & & & \\
\hline B2 & $\mathrm{t}$ & $\mathrm{t}$ & 106 & 83430.4 & 13.7 & & & \\
\hline B3 & $\mathrm{t}$ & . & 87 & 83662.0 & 207.3 & & & \\
\hline B4 & c96 & $\mathrm{t}$ & 88 & 83463.1 & 10.4 & 28.97 & $<10^{-4}$ & 0.62 \\
\hline B5 & $\mathrm{c} 96+\mathrm{N}_{<0}+\mathrm{P}_{\text {tot }}$ & $\mathrm{t}$ & 90 & 83458.7 & 10.0 & 10.73 & $<10^{-4}$ & 0.67 \\
\hline B6 & c96+T & $\mathbf{t}$ & 89 & 83450.7 & 0.0 & 27.29 & $<10^{-4}$ & 0.76 \\
\hline B7 & c96 $+\mathrm{N}_{<0}+\mathrm{P}_{\text {tot }}+\mathrm{T}$ & $\mathbf{t}$ & 91 & 83447.1 & 0.4 & 15.40 & $<10^{-4}$ & 0.80 \\
\hline
\end{tabular}




\section{Figure legends}

Fig. 1 Monthly survival probabilities in winter of adults banded in a low-hunting area. Black dots: estimates from Model A2 (full, unconstrained time-dependence). Vertical lines: 95\% confidence intervals on these estimates. Bold line: estimates from preferred Model A5 (temporal variation explained by the additive effect of two weather variables and a temporal trend). On the x-axis the year corresponds to the beginning of the winter, e.g., 1990 stands for the period from Oct 1990 to Feb 1991. Survival probability for juveniles followed the same temporal variation in the model.

Fig. 2 Probabilities to migrate from France to Spain during the winters. Black dots: estimates from Model B1 (full, unconstrained time-dependence). Vertical lines: 95\% confidence intervals on these estimates. Bold line: estimates from Model B7 (temporal variation explained by the additive effect of the 1996-1997 cold spell, of weather indexes and of a temporal trend). On the x-axis the year corresponds to the beginning of the winter, e.g., 1990 stands for the period from Oct 1990 to Feb 1991. 
Figures

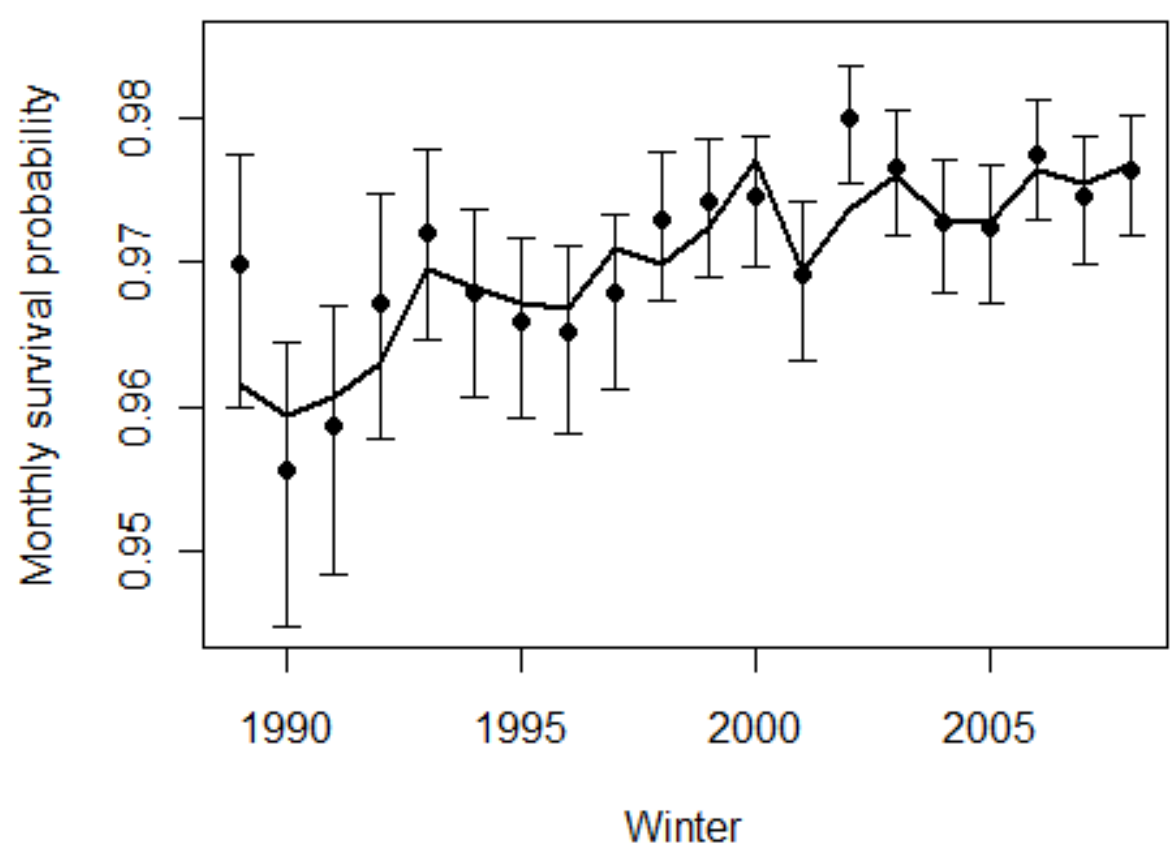




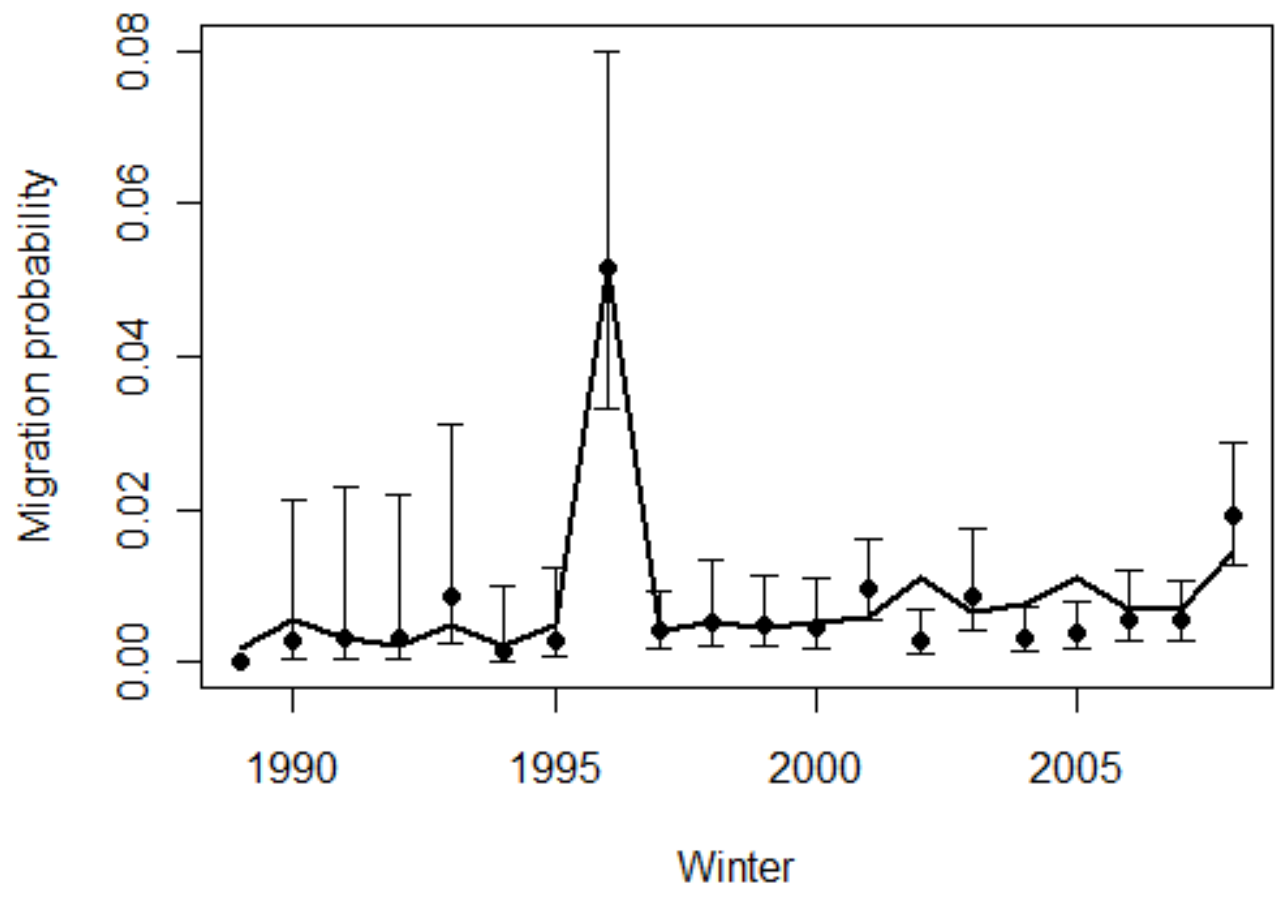

